\title{
The Willingness to Pay for Local, Domestic, and Imported Bundled Fresh Produce by Online Shoppers
}

\author{
Jean D. Gumirakiza ${ }^{1} \&$ Taylor Choate ${ }^{1}$ \\ ${ }^{1}$ Department of Agriculture, Western Kentucky University, Bowling Green, KY, USA \\ Correspondence: Jean D. Gumirakiza, Western Kentucky University, Department of Agriculture, EST 237, 1906 \\ College Heights BLVD \# 410066, Bowling Green, KY 42101. Tel: 1-270-363-7134. E-mail: \\ dominique.gumirakiza@wku.edu
}

Received: August 9, 2018

doi:10.5539/jas.v10n12p15
Online Published: November 15, 2018

URL: https://doi.org/10.5539/jas.v10n12p15

The research is financed by the USDA-NIFA.

\begin{abstract}
This study applies a Censored Normal Tobit Model on the 2016 survey data from 1,205 online shoppers in the South region of the United States to explain their Willingness To Pay (WTP) for a bundle of fresh produce from different origins. This study indicates that online shoppers are willing to pay $\$ 6.91, \$ 6.38$, and $\$ 5.22$ for four pounds of bundled fresh produce that are locally, domestically grown, and imported respectively. We found that income category, interests in online shopping, interest level for local, interest level for organic, and monthly spending on fresh produce have a significant positive impact on the WTP for locally grown fresh produce. Results indicate that being married, high income, interests in online shopping, interests in local produce, interests in organic, and the monthly spending on fresh produce increase the WTP for domestically grown fresh produce, while age and being a female diminishes it. We further found that age, being a female, and interest in the freshness of the produce decrease the WTP for imported produce. Based on the findings from this study, we have suggested a couple of marketing implications and suggestions.
\end{abstract}

Keywords: Tobit model, online shoppers, local, domestic, and imported fresh produce

\section{Introduction}

Online shopping is increasingly growing as more consumers trust the online marketplace. Products of various sort are currently available in this type of marketplace. In fact, grocery stores like Walmart and Kroger have recently started offering an option for customers to order food products online with pickup service. Likewise, Amazon, (2018) has an online store for fresh produce. There are a variety of labels that are used to identify fresh produce as local, domestic, or foreign/imported. The question for this study is how much consumers in the online marketplace are willing to pay more for fresh produce on the basis of their origin.

Several previous studies (Frost, 2017; Gumirakiza et al., 2015; Strailey, 2014; Gumirakiza et al., 2014; Curtis et al., 2014; Lang, 2010; Mouser et al., 2011; Velasquez et al., 2005) have looked at the consumer preferences for locally grown produce focusing mainly on direct-to-consumer market outlets like farmers' markets. In contrast, this study targets online shoppers and explain their Willingness To Pay (WTP) for fresh produce grown in their state or within a 400-radias (local), USA (domestic), and abroad (imported). Among many questions, we asked online shoppers to indicate the amounts of money they would be willing to pay for a pound of various types of fresh produce if they are locally grown, domestically grown, or imported from abroad. The specific objectives for this study are to (1) determine the online shoppers' WTP for locally grown bundled fresh produce, (2) determine the online shoppers' WTP for domestically grown bundled fresh produce, and (3) determine the online shoppers' WTP for foreign/imported bundled fresh produce.

This study is valuable for the market players to develop marketing strategies targeting "local", "domestic" or "foreign" produce. The study identifies consumer's characteristics with significant effects on the WTP amounts. Determining whether people are willing to pay more for locally grown, domestic, or foreign produce will allow agricultural marketers to make informed decisions as they continue exploring market opportunities within the online environment. Differences in the WTP are beneficial for agricultural marketers for the purpose of pricing 
strategies within the online marketplace. This study is also beneficial to the research community in furthering understanding of consumer preferences for fresh produce among online shoppers.

\section{Literature Review}

Consumers have become increasingly concerned with where their produce is coming from (Lang, 2010; Velasquez et al., 2005). These studies focused on the demographics and psychographics of those who purchase locally grown produce, or those who utilize farmers markets or CSA programs. Locally grown is a large growing slogan for marketing campaigns. Data shows that the desire for local has even out ranked that of organic and the need for local is surpassing the supply available (Strailey, 2017). There are other studies that focus on why consumers are choosing local produce as their first choice and what importance it has to them (Frost, 2017). Consumers who buy locally-grown produce do so largely because they associate local origin with attributes that are very important in fruits and vegetables such as superior taste, freshness, and appearance (Velasquez, 2005). According to Strailey (2014), an online poll of U.S adults, 55\% of consumers purchased local to support local businesses, $41 \%$ believed local produce is fresher, $20 \%$ thought it was better for the environment, $17 \%$ purchased local because they believed it has greater nutritional value and $16 \%$ thought it was safer than nonlocal products.

Producing locally grown produce can be challenging and even costly endeavor. Locally grown produce must be grown in staggering intervals to ensure all produce is available and ripe for one short harvest. The average harvest season must be extended for the longest time possible to provide an assortment of produce year-round. In the U.S a large portion of the country does not have the climate required for production of various products, this can require the use of greenhouses in order to produce the desired products, in areas that they typically would not yield well. 80 miles west of Chicago nearly 7 million pounds of hydroponic tomatoes were harvested this year from two 7.5-acre greenhouses in order to provide for the local produce demand (Frost, 2017).

There are studies that reported that consumers are willing to pay more for foods produced locally. Boys et al. (2013) found that consumers would pay a 12 percent premium for locally grown produce relative to produce supplied and produced by conventional sources. Darby (2006) found that in the case of fresh strawberries, customers at direct markets would pay nearly $\$ 1.17$ more per carton of strawberries that was grown locally rather than berries identified simply as produced in the U.S. The variation of willingness to pay for local produce may also differ depending on the individual product and also in the market setting in which consumers chose to purchase their produce. According to George (2010), majority of her respondents were willing to pay at least a slight premium for their local foods, and of those respondents $16.9 \%$ were willing to pay up to a twenty-five percent premium. Onozaka and Mcfadden (2011) found a positive WTP value for local produce over both domestic and imported produce; suggesting that consumers have a higher preference of supporting producers in their direct area. According to Goddard et al. (2012), imported steak is on average less preferred by consumers across all education, income, and age levels, as compared to domestically grown. Burnett et al. (2011) determined that on a scale of grown in the Midwest, in state, and in county, there were variations in consumers' willingness to pay premiums. As the area was a closer parameter, it showed a positive correlation with price premiums.

However, there are some cases where consumers also have preferences of origin based on the association of the highest quality, which can affect their preference of domestic over local. For example, Progressive Grocer (2014) indicated that several consumers prefer Idaho grown potatoes over those grown in their locations. George (2010) concluded that that although local foods did have substantial importance to respondents, over $50 \%$ of the respondents would choose better products from other specific regions. Likewise, some consumers choose to make purchase decisions based on the environmental techniques used in specific areas. If a consumer with high environmental priorities knows product techniques regardless of the location proximity to themselves they may purchase from the area with the highest environment conservation practices (Maples et al., 2014).

\section{Methodology}

\subsection{Data Collection}

This study used online-based survey data from online shoppers in the South region of the United States (U.S. Census Bureau, 2016). In this study, online shoppers are those consumers who purchased online at least two times in six months before they completed our survey. The survey was distributed and completed in 2016 from early March to the end of July. We randomly and proportionally (based on state's population) selected study participants. The survey questions were formulated in the Qualtrics software; which then generated a link to be distributed to study participants. The Qualtrics company is a professional provider of survey software. The company provides advanced and sophisticated techniques to collect data within online environment. The company works with more 
than 20 online panel providers to find a quality pool of respondents based on sample requirements specified by researchers. The software has the capability to verify every Internet Protocol address for the purpose of data validity and quality. It made possible for us to profile, track, and monitor each response accurately. We designed survey questions using features that embedded in the software to allow branching logic, blocking unnecessary questions, and question randomization. We used these features to avoid possible biases during survey taking. Furthermore, we included special questions designed to eliminate inattentive participants. Those respondents who failed to give the correct answer to such questions were automatically excluded from the study. All these strategies increased the quality and validity of the data. We let the survey link to stay active until we reached 1,205 valid responses.

\subsection{Variables of Interest}

The dependent variable in this study consists of amounts of money respondents are willing to pay for a "basket" of a bundled fresh produce. The types of fresh produce that we bundled in "basket" are: green beans, Roma tomatoes, kale, and strawberries. In this paper, we use the phrase "bundled fresh produce" to refer to the produce in this "basket". Respondents were asked to indicate how much they are willing to pay for a pound of each of the produce types. Because we have bundled the produce types together in one "basket" containing a pound of each, we horizontally added the WTP to obtain how much each respondent is willing to pay for the "basket". To determine an upper limit to be used in the Censored Tobit model, we collected information about the actual market prices of the bundled fresh produce from Walmart, Kroger, and Amazon stores. We then computed the average price for each produce type. We finally doubled the computed average price to create a price range with the mean being in the center from zero to the upper limit. For example, average price for Roma tomatoes was $\$ 2.00$. As a result, the upper limit became $\$ 4$. Consequently, response amounts that were greater than 4 were censored. An upper limit prevented respondents from overstating the WTP amounts. We did not make a lower limit because we wanted to allow a possibility of zero responses for those who would not purchase the specific type of the fresh produce in the "basket". This strategy allowed us to create a more realistic price range and truncate the amounts that were beyond the range.

The independent variables are the chooser's characteristics. We included those that are significant and/or relevant to explain the WTP. We first run our model with all respondent's characteristics and conducted model specification tests to remove unnecessary variables. We finally retained fifteen variables. There is age, gender (1 for female and 0 otherwise), and marital status ( 1 for married and 0 otherwise). "Locavore" variable is a binary representing those respondents who regularly eat more fresh produce for dietary purposes. Other variables are levels of education, Caucasian ( 1 for Caucasian and 0 otherwise), and InterestedInCSA [ 1 for those who are or would join Community Supported Agriculture (CSA) programs and 0 otherwise]. The "AboveAverageIncome" variable gets 1 if the respondent's income is above average income and 0 otherwise. The "InterestOnlineShopFP" variable stands for a 1-3 scale levels of interest respondents have in shopping for fresh produce online. The "InterestLearnFPMarket" is a dummy variable with 1 being interested in learning about markets for fresh produce and 0 otherwise. The "InterestLevelLocalFP" variable represents 1-5 scale levels of interest in locally grown fresh produce. The "InterestLevelOrganicFP" variable represents 1-5 scale levels of interest in respondents have in fresh produce that is organically grown. The "InterestLevelFreshness" variable is for 1-5 scale levels of interests in the freshness of the produce. Finally, the "MonthlySpendFreshProduce" variable represents the estimated average amounts of money respondents spend on fresh produce each month. To avoid including highly correlated independent variables we tested for the possible correlation. The highest correlation coefficient that we found was 0.59 between the "InterestLevelFreshness" and the "InterestLevelLocalFP". With reference to Wooldridge (2009), who suggested a maximum coefficient value of 0.80 , there is no evidence of worrisome correlation among explanatories.

\subsection{Theoretical Modeling}

The nature of the dependent variable makes it appropriate to use a Censored Normal Tobit Model as recommended by Tobin (1958), Greene, (2008), and Kennedy (2008). Schott and Bernard (2015) used a similar modeling strategy to analyze consumer's willingness to pay for conventional, non-conventional organic and organic milk from small and large farms.

Conceptually, let $\mathrm{W}$ be the limited dependent variable, with an upper limit of $\mathrm{U}$. the limit is the same for all respondents. Let $\mathrm{Y}$ denote a linear combination of independent variables $\left(\mathrm{X}_{1}, \mathrm{X}_{2}, \mathrm{X}_{3}, \ldots \mathrm{X}_{\mathrm{k}}\right)$, so that:

$$
\mathrm{Y}=\beta_{0}+\beta_{1} \mathrm{X}_{1}+\beta_{2} \mathrm{X}_{2}+\beta_{3} \mathrm{X}_{3}+\ldots+\beta_{\mathrm{k}} \mathrm{X}_{\mathrm{k}}+\varepsilon
$$

The $\varepsilon$ is a random variable which counts for differences in the response variable that are not explained by the independent variables $\mathrm{X}$ and the upper limit $\mathrm{U}$. This random variable is assumed to have zero mean, standard 
distribution $\sigma$, and normally distributed across online shoppers. Therefore, the respondent's behavior is assumed to be as follows:

$$
\mathrm{W}=\mathrm{U} \text { when }(\mathrm{Y}-\varepsilon>\mathrm{U}) ; \mathrm{W}=\mathrm{Y}-\varepsilon \text { when }(\mathrm{Y}-\varepsilon \leq \mathrm{U})
$$

Let now $\mathrm{S}(\mathrm{x})$ represent the value of the cumulative unit-normal distribution function at $\mathrm{x}$, let $\mathrm{G}(\mathrm{x})=1-\mathrm{S}(\mathrm{x})$, and let $\mathrm{D}(\mathrm{x})$ be the value of the unit-normal probability density function at $\mathrm{x}$. Therefore, for specified values of $\mathrm{Y}$ and the limit $\mathrm{U}$, we can derive the probability distribution as follows:

$$
\begin{gathered}
\operatorname{Pr}(\mathrm{W}=\mathrm{UIY}, \mathrm{U})=\operatorname{Pr}(\varepsilon>\mathrm{U}-\mathrm{Y})=\mathrm{G}\{(\mathrm{U}-\mathrm{Y}) / \sigma\} \\
\operatorname{Pr}(\mathrm{W}<\mathrm{x} \leq \mathrm{UIY})=\operatorname{Pr}(\mathrm{Y}-\varepsilon<\mathrm{x})=\operatorname{Pr}(\varepsilon>\mathrm{Y}-\mathrm{x})=\mathrm{S}\{(\mathrm{Y}-\mathrm{x}) / \sigma\}
\end{gathered}
$$

The corresponding probability density function is:

$$
\mathrm{f}(\mathrm{x} ; \mathrm{Y}, \mathrm{U})=\frac{1}{\sigma} \mathrm{D}\{(\mathrm{Y}-\mathrm{x}) / \sigma\}
$$

The expected value of $\mathrm{W}$ for given values of $\mathrm{Y}$ and $\mathrm{U}$ is:

$$
\mathrm{E}(\mathrm{W} ; \mathrm{Y}, \mathrm{U})=\mathrm{UG}\{(\mathrm{U}-\mathrm{Y}) / \sigma\}+\int_{0}^{\mathrm{U}} \frac{\mathrm{x}}{\sigma} \mathrm{D}\{(\mathrm{Y}-\mathrm{x}) / \sigma\} \mathrm{dx}
$$

The marginal effect on the expected value of $\mathrm{Y}$ is given by:

$$
\frac{\partial \mathrm{E}(\mathrm{W} ; \mathrm{Y}, \mathrm{U})}{\partial \mathrm{x}_{\mathrm{k}}}=\phi\left(\frac{\mathrm{X}_{\mathrm{i}} \beta}{\sigma}\right) \beta_{\mathrm{k}}
$$

The $\phi\left(\mathrm{X}_{\mathrm{i}} \beta / \sigma\right)$ represents the estimated probability of observing a non-censored observation at the values of $\mathrm{X}$. As this scale factor moves closer to one; meaning fewer censored observations; the adjustment factor (the estimate probability) loses its effect and the coefficient $\beta_{\mathrm{k}}$ actually becomes the marginal effect the particular values of $\mathrm{X}$.

This study's hypothesis is two-fold; the null and the alternative. The null hypothesis is that each of the independent variable $X_{k}$ has no significant effect on the willingness to pay for bundled fresh produce among online shoppers. The alternative hypothesis is that each of the independent variable $X_{k}$ significantly affect the willingness to pay for bundled fresh produce among online shoppers either negatively or positively.

\section{Results}

\subsection{Descriptive Statistics}

Table 1 below shows descriptive statistics for the variables of interest. An average online shopper that participated in this study is 47 years old, completed a 2-year associate's degree, and spends an average of almost $\$ 58$ on fresh produce per month. Our respondents were composed of 62 percent females, 56 percent married, and 72 percent locavores.

Table 1. Mean and standard deviation for the variables of interests

\begin{tabular}{lll}
\hline Description/Variable & Mean & Standard Deviation \\
\hline Age & 47 years old & 2.507 \\
Female & 0.617 & 0.486 \\
Married & 0.560 & 0.497 \\
Locavore & 0.724 & 0.447 \\
Education & 3.364 & 1.117 \\
Caucasian & 0.820 & 0.384 \\
InterestedInCSA & 0.505 & 0.500 \\
AboveAverageIncome & 0.368 & 0.482 \\
InterestOnlineShopFP & 2.022 & 0.859 \\
InterestLearnFPMarket & 0.806 & 0.396 \\
InterestLevelLocalFP & 3.873 & 1.052 \\
InterestLevelOrganic & 3.269 & 1.358 \\
InterestLevelFreshness & 4.377 & 0.863 \\
MonthlySpendFreshProduce & $\$ 57.831$ & 68.439 \\
WTPLocal & $\$ 6.590$ & 2.507 \\
WTPDomestic & $\$ 6.099$ & 2.664 \\
WTPImported & $\$ 5.066$ & 2.794 \\
\hline
\end{tabular}


Results in Table 1 suggest that almost 51 percent of online shoppers are enthusiastic about CSA programs. Only 37 percent reported having annual income that is above the respondents' average income. It appears that those who are actively engaged in online marketplace are not necessary the affluent individuals. On a scale of 1-3 levels of interest ( 1 being not interested, 2 being somehow interested, and 3 being interested) in shopping fresh produce online, the statistics indicate that online shoppers are somehow interested in purchasing fresh produce online. This seems to be a neutral situation that needs further investigation. We found that a grand majority of these online shoppers are willing to be aware of market outlets that are available in their communities for fresh produce. This result is important for marketers within the locally grown fresh produce movement. Indeed, we found that on a scale of 1-5 levels of interest in local fresh produce, online shoppers are very interested. They are almost extremely interested in the freshness of the produce. On average, they indicated that they would be willing to pay more $(\$ 6.59)$ for a "basket" of locally grown compared to approximately $\$ 6.10$ for the same basket of domestically grown and barely $\$ 5.10$ for imported "basket". The Censored Normal Tobit regression used in this model (see results below) produced WTP results that are very close to these means. This indicates that we employed the right and appropriate model.

\subsection{Regression Results}

This study sought to analyze the willingness to pay for bundled fresh produce that are locally, domestically, or foreign grown. Table 2 shows predicted WTP amounts; which were computed using delta method and predict command available in Stata software after running the Censored Normal Tobit regression. We also computed 95\% confidence intervals within which our predicted WTP amounts are likely to be found. The WTP results are shown for locally grown, domestically grown, and imported fresh produce.

Table 2. Predicted WTP amounts after the censored normal Tobit regression

\begin{tabular}{llllll}
\hline \multirow{2}{*}{ Description } & Predicted WTP Amount & Standard Error & \multirow{2}{*}{ P-Value } & \multicolumn{2}{c}{$95 \%$ Confidence Interval } \\
\cline { 5 - 6 } & & & & Lower & Upper \\
\hline WTPLocal & $\$ 6.91$ & .083 & .000 & $\$ 6.752$ & $\$ 7.076$ \\
WTPDomestic & $\$ 6.38$ & .086 & .000 & $\$ 6.207$ & $\$ 6.544$ \\
WTPImported & $\$ 5.22$ & .082 & .000 & $\$ 5.059$ & $\$ 5.382$ \\
\hline
\end{tabular}

Results of the model indicate that online shoppers' WTP for a basket of four pounds of locally grown bundled fresh produce (green beans, Roma tomatoes, kale, and strawberries) is almost $\$ 7.00$. We are 95 percent confident that this predicted WTP amount fluctuates within a range of $\$ 6.75$ and $\$ 7.07$. As for the domestically grown bundled fresh produce, online shoppers are willing to pay $\$ 6.38$ for the basket. We are 95 percent confident that this predicted WTP amount could vary from $\$ 6.21$ and $\$ 6.54$. As expected, we finally found that online shoppers are willing to pay less (\$5.22) for the same size of basket containing bundled fresh produce that is grown abroad. We are 95 percent confident that this predicted WTP amount fluctuates within a range of $\$ 5.06$ and $\$ 5.38$. These results clearly support the findings by Boys et al. (2013), George (2010), and Onozaka and McFadden (2011) that consumers are willing to pay a premium for locally grown fresh produce.

A censored normal Tobit model was used to analyze data with 1,205 total observations for the fourteen independent variables. The regression analysis was conducted separately for local, domestic, and imported fresh produce. Table 3 shows marginal effects; which were computed in Stata software using $\mathrm{mfx}$ command after running the regression. As in Greene (2005), the marginal effects from this type of model are partial effects obtained by multiplying coefficient and the probability attached to the non-censored region. For continuous independent variables such as age and "MonthlySpendFreshProduce", marginal effects are interpreted as the change in predicted WTP as a result of a unit change in the corresponding explanatory variable, holding all other factors in the model constant. For discrete explanatory variables, the marginal effects are the differences in the predicted WTP from one level to the next upwards. For dummy (binary) variables, the marginal effects are differences in the WTP between a category of 0 and that of 1 . For example, in the case of marital status, the marginal effect of the variable married is computed as the difference in the estimated WTP between married $=1$ and married $=0$ (single individual). Results are presented for local, domestic, and imported fresh produce. 
Table 3. Censored normal tobit coefficient estimates and marginal effects results

\begin{tabular}{|c|c|c|c|}
\hline Description/Variable & WTPLocal & WTPDomestic & WTPImported \\
\hline Age & $-.014 * * *$ & $-.016 * * *$ & $-.027 * * *$ \\
\hline Female & $-.575 * * *$ & $-.481 * * *$ & $-.599 * * *$ \\
\hline Married & $.319^{* *}$ & $.431 * *$ & .197 \\
\hline Locavore & .217 & .151 & .047 \\
\hline Education & .066 & .047 & .101 \\
\hline Caucasian & $.399 * *$ & .088 & $-.371^{*}$ \\
\hline InterestedInCSA & .088 & -.210 & -124 \\
\hline AboveAverageIncome & $.311^{*}$ & $.533 * * *$ & $.524 * * *$ \\
\hline InterestOnlineShopFP & $.733 * * *$ & $.628 * * *$ & $.388 * * *$ \\
\hline InterestLearnFPMarket & -.169 & -.232 & -.232 \\
\hline InterestLevelLocalFP & $.377 * * *$ & $.192 *$ & .105 \\
\hline InterestLevelOrganic & $.342 * * *$ & $.293 * * *$ & $.281 * * *$ \\
\hline InterestLevelFreshness & -.138 & -.107 & $-.308 * * *$ \\
\hline MonthlySpendFreshProduce & $.006^{* * *}$ & $.005^{* * *}$ & $.003^{* * *}$ \\
\hline \multicolumn{4}{|l|}{ Statistics } \\
\hline $\mathrm{N}$ & 1205 & 1205 & 1205 \\
\hline LR chi2(14) & 216.88 & 185.56 & 225.28 \\
\hline Prob $>$ chi 2 & .000 & .000 & .000 \\
\hline Pseudo R2 & .0402 & .0333 & .0389 \\
\hline Left-censored observations & 0 & 0 & 0 \\
\hline Uncensored observations & 960 & 994 & 1068 \\
\hline Right-censored observations & 245 & 211 & 137 \\
\hline
\end{tabular}

Note. The $*, * *, * * *$ denote significance at the $10 \%, 5 \%$, and $1 \%$ level, respectively.

Results in Table 3 show that factors with statistically-significant impact on the WTP for locally grown fresh produce are: age, gender, marital status, race, category of income, interest in online shopping, interest level for local, interest level for organic, and the monthly spending on fresh produce. Factors that are significant in influencing the WTP for domestically grown fresh produce are: age, gender, marital status, category of income, interest in online shopping, interest level for local, interest level for organic, and the monthly spending on fresh produce. We further found that the WTP for imported fresh produce is explained by age, gender, race, category of income, interests in online shopping, interests in organic, interests in the produce freshness, and the monthly spending on fresh produce. There is no evidence to suggest that education, locavore, and interest in CSA programs among online shoppers have any significant effect on the WTP for either locally grown, domestically, or imported fresh produce. Likewise, we found that race and interests in the produce freshness have no significant impact on the WTP for domestically grown fresh produce. As expected, we found that interests in the produce freshness diminishes the WTP for imported fresh produce.

We found that age and being a female are negatively associated with the WTP for locally grown fresh produce. In fact, ten more years of age leads to $\$ 1.40$ lower in the amount an online shopper would be willing to pay for local fresh produce. This number gets even bigger for domestically grown and imported bundled fresh produce with $\$ 1.60$ and $\$ 2.70$ respectively. This finding indicates that younger online consumers would pay more than what older individuals are willing to pay. Results show that compared to males, females are willing to pay 58 cents lower for the locally grown fresh produce, 48 cents lower for the domestically grown fresh produce, and 60 cents lower for the imported fresh produce. This result is similar to George (2010) who reported that the WTP for local fresh produce decreased for females. We further found that while Caucasians are willing to pay 40 cents more for local fresh produce than what their counterparts would pay, they are willing to pay 37 cents less for imported produce.

This study indicates that affluent (those whose annual income is above respondents' average income) consumers are willing to pay more than their counterparts. Surprisingly though, we found that they would pay almost 21 cents more for imported fresh produce than they would pay for locally grown produce. The opposite would make 
more sense. The domestically grown fresh produce command the highest WTP amounts among this category of shoppers. They are willing to pay 53 cents more than the below-average income individuals.

This study's results show that those with high interests in shopping for fresh produce online are willing to pay more for locally grown fresh produce than for domestic (beside local) or imported fresh produce. One more level of interest in online shopping for fresh produce increases the WTP by 73 cents, 63 cents, and 39 cents for local, domestic, and imported produce respectively. This finding posits that those with interests in shopping fresh produce online would like to spend more in their local economies on fresher produce and support by farmers in their communities.

Obviously, results indicate that those shoppers with higher interests in local fresh produce would be willing to pay more. One more level of interest in local produce increases the WTP by 38 cents. The effect becomes smaller (19 cents) and barely significant for domestically grown produce. There is evidence to suggest a significant effect of interests in local fresh produce on the WTP for imported fresh produce. In other words, as consumers increase their preferences for locally grown produce, there is no willingness to pay for the same imported fresh produce. Among those organic-preferred shoppers, results indicate that they are willing to pay more for locally grown fresh produce than for domestic or imported fresh produce. One more level of interest in organically grown fresh produce increases the WTP by 34 cents, 29 cents, and 28 cents for local, domestic, and imported produce respectively.

Interestingly, interests in the freshness of the produce have no significant effect on the WTP for locally or domestically grown fresh produce. Instead, the impact is negatively significant on the WTP for imported produce. One more level of interests in freshness diminishes the WTP for an imported basket of the fresh produce by 31 cents. Finally, this study's results indicate that those with higher monthly expenditures on fresh produce in general are willing to pay more for local, domestic, and imported produce. Additional $\$ 100$ spent on fresh produce per month would increase the WTP by 60 cents, 50 cents, and 30 cents for locally grown, domestically grown, and imported fresh produce, respectively.

\section{Concluding Remarks}

Today, online shopping is increasingly gaining momentum among consumers. While the existing literature is heavily focused on consumer preferences for fresh produce in the offline marketplace, this study is one of the few that targets online shoppers to analyze their WTP for fresh produce. In the context of this study, online shoppers are those consumers who purchased any product online at least twice within six months before they participated in this study in 2016. There were randomly and proportionally selected 1,205 online shoppers who responded to our survey. The study was limited to those online shoppers that reside in the Southern region of the U.S. We used Qualtrics to collect data. We bundled green beans, Roma tomatoes, kale, and strawberries together in one "basket" containing a pound of each. For each of these types of produce, respondents indicated the amount of money they were willing to pay per pound. We then created a realistic price range based on actual market prices of the produce in the "basket". Those respondents' amounts that fell above the upper limit were censored. Given the type of data in the dependent variable, we used a Censored Normal Tobit Model.

Major results from this study indicate that online shoppers are willing to pay $\$ 6.91$ for locally grown bundled fresh produce, $\$ 6.38$ for domestically grown, and $\$ 5.22$ for imported fresh produce. Factors that have significant positive impact on the WTP for locally grown fresh produce are: marital status (being married), race (being Caucasian), income category, interest in online shopping, interest level for local, interest level for organic, and the monthly spending on fresh produce. Age and being a female have a negative impact on this WTP. Furthermore, results indicate that being a male, married, income category, interest in online shopping, interests in local produce, interests in organic, and the monthly spending on fresh produce increase the WTP for domestically grown fresh produce, while age diminishes it. This study found that age, gender, race, and the produce freshness affect the WTP for imported produce negatively while income category, interests in online shopping, interests in organic, and the monthly spending on fresh produce influence it positively.

Findings from this study suggest a couple of marketing implications and/or suggestions. Online shoppers are willing to pay more for locally grown fresh produce than they are for either domestically grown or imported produce. This suggests that local farmers and/or marketers of local fresh produce would increase their sales revenue in case they target online shoppers. The findings also suggest that the agribusinesses in the fresh produce movement will do better online carrying more locally grown produce in comparison with domestically and imported produce. Results further suggest that sellers of the fresh produce who intend to increase prices would target males and younger individuals as they were found to be willing to pay more for fresh produce, regardless of the origin (local, domestic or imported). Females and old people prefer paying less. This study further 
suggests that fresh produce marketers should target affluent consumers because we found that those respondents with income that above the average are WTP more for fresh produce. Marketers of fresh produce are encouraged to revise their marketing strategies based on the shoppers' characteristics we found to be significant. Finally, we suggest that future research studies should employ other methods like conjoint analysis to estimate WTP for fresh produce among online shoppers. They might also investigate the WTP for a single/specific type of fresh produce like strawberries instead of a "basket" of several produce types.

\section{References}

Amazon. (2018). Amazon Fresh Grocery. Retrieved from https:/www.amazon.com/AmazonFresh-Grocery/ $\mathrm{b}$ ? $\mathrm{ie}=\mathrm{UTF} 8 \&$ node $=11825099011$

Boys, K. A., Willis, D. B., \& Carpio, C. E. (2013). Consumer willingness to pay for organic and locally grown produce on Dominica: Insights into the potential for an "Organic Island". Environment Development and Sustainability, 16(3), 595-617. https://doi.org/10.1007/s10668-013-9496-3

Burnett, P., Kuethe, T. H., \& Price, C. (2011). Consumer preference for locally grown produce: An analysis of willingness-to-pay and geographic scale. Journal of Agriculture, Food Systems, and Community Development, 2(1), 269-278.

Curtis, K. R., Gumirakiza, J. D., \& Bosworth, R. (2014). Consumer Preferences and Willingness to Pay for Multi-Labeled Produce at Farmers' Markets. Journal of Food Distribution Research, 45(1), 14-20.

Darby, K., Batte, M. T., Ernst, S., \& Roe, B. (2006). Willingness to pay for locally produced foods: A customer intercept study of direct market and grocery store shoppers. Columbus, $\mathrm{OH}$ : Ohio State University. Retrieved from https://www.researchgate.net/publication/23506618_Willingness_to_Pay_for_Locally_ Produced_Foods_A_Customer_Intercept_Study_of_Direct_Market_and_Grocery_Store_Shoppers

Frost, P. (2017). Farm Fresh-Everyday. Crain's Chicago Business, 40(9), 1-3.

George, S., (2010). Willingness to pay for locally grown and organically produced fruits and vegetables in Dominica (p. 874). TigerPrints, Clemson University.

Goddard, E., Hu, W., Lim, K. H., \& Maynard, L. J. (2012). U.S. Consumers' Preference and Willingness to Pay for Country-of-Origin-Labeled Beef Steak and Food Safety Enhancements. Canadian Journal of Agricultural Economics, 61(1), 93-118.

Greene, W. H. (2005). Censored Data and Truncated Distributions. Retrieved from https://ssrn.com/abstract= 825845

Greene, W. H. (2008). Econometric Analysis (6th ed.). Upper Saddle River, New Jersey: Pearson Prentice Hall.

Gumirakiza, J. D., Curtis, K. R., \& Bosworth, R. (2014). Who Attends Farmers' Markets and Why? Understanding Consumers and their Motivations. International Food and Agribusiness Management Review, 17(2), 65-82.

Gumirakiza, J. D., Curtis, K. R., \& Bosworth, R. (2015). Farmers Market Consumer Preferences for Fresh Produce Attributes: Marketing and Policy Implications. Journal of Agribusiness, 33(1), 63-81.

Kennedy, P. (2008). A Guide to Econometrics (6th ed.). Malden, Massachusetts: Blackwell Publishing.

Lang, K. B. (2010). The Changing Face of Community-Supported Agriculture. Culture \& Agriculture, 32(1), 17-26. https://doi.org/10.1111/j.1556-486X.2010.01032.x

Maples, M., Morgan, K. L., Harri, A., Hood, K., \& Interis, M. (2014). Consumer Willingness to Pay for Environmental Production Attributes in Tomatoes: A Southeastern Consumer Survey. Selected Paper for Presentation at the 2014 Annual Meeting of the Southern Agricultural Economics Association, February 1-4, Dallas, TX.

Mouser, R., Raffaelli, R., \& Thilmany-McFadden, D. (2011). Consumer Preferences for Fruit and Vegetables with Credence-Based Attributes: A Review. International Food and Agribusiness Management Review, 14(2), 121-142.

Onozaka, Y., \& McFadden, D. T. (2011). Does Local Labeling Complement or Compete with Other Sustainable Labels? A Conjoint Analysis of Direct and Joint Values for Fresh Produce Claim. American Journal of Agricultural Economics, 93(3), 693-706. https://doi.org/10.1093/ajae/aar005

Progressive Grocer. (2014). A sense of place: Where potatoes were grown impacts purchase decisions. Progressive Grocer, 93(12), 4. 
Schott, L., \& Bernard, J. C. (2015). Comparing Consumer's Willingness to Pay for Conventional, Non-Certified Organic and Organic Milk from Small and Large Farms. Journal of Food Distribution Research, 46(3), 186-205.

Strailey, J. (2014). Vocal for Local. Progressive Grocer, 93(8), 123.

Strailey, J. (2017). Winter Wonderland: Consumer demand for local, color and quality in the produce department is redefining what's in season. Progressive Grocer, 96(11), 66-67.

Tobin, J. (1958). Estimation of Relationship for Limited Dependent Variables. Econometrica, 26(1), $24-36$. https://doi.org/10.2307/1907382

U.S. Census Bureau. (2016). Census Regions and Divisions of the United States. Retrieved from http://www2.census.gov/geo/pdfs/maps-data/maps/reference/us_regdiv.pdf

Velasquez, C., Eastman, C., \& Masiunas, J. (2005). An Assessment of Illinois Farmers' Market Patrons' Perceptions of Locally-Grown Vegetables. Journal of Vegetable Science, 11(1), 17. https://doi.org/10.1300/ J484v11n01_03

\section{Copyrights}

Copyright for this article is retained by the author(s), with first publication rights granted to the journal.

This is an open-access article distributed under the terms and conditions of the Creative Commons Attribution license (http://creativecommons.org/licenses/by/4.0/). 